\title{
Tomographic aspects of xanthogranulomatous pyelonephritis and related complications
}

\author{
Department of Imagery Diagnosis, Paulist School of Medicine, Federal University of São Paulo - São Paulo, Brazil
}

The authors present their experience involving seven patients with histopathologic diagnosis of xanthogranulomatous pyelonephritis who were submitted to preoperative computed tomography (CT). The results are the following: a) stones ( 86 percent of the cases), b) increase in renal volume, c) hydronephrosis, d) density measurements (from 14 to $29 \mathrm{HU}$ ), e) enhancement found in all cases, f) extrarenal involvement (all cases). CT has shown to be a reliable method in characterizing xanthogranulomatous xyelonephritis and extrarenal involvement.

UNITERMS: Pyelonephritis. Computed Tomography.

\section{INTRODUCTION}

$\mathrm{X}$ anthogranulomatous pyelonephritis (XGP) is an atypical variety of a chronic renal infection which urinary obstruction and stones ${ }^{13.15}$. Before ultrasonography (US) and computed tomography, (CT) preoperative diagnosis was not certain in 44-64 percent of all cases, due especially to uncharacterized symptoms, and laboratory exams that showed no alterations ${ }^{5}$. 13. 16. 18. Radiographic exams such as excretory urogram (EU) and antegrade pyelography (APG) allow the diagnosis of a renal mass with or without functional elimination; however, they do not indicate the degree of inflammation caused by the disease ${ }^{13}$. Although it is relatively rare $(820$

\section{Address for correspondence:}

Giuseppe D'lppolito

Rua Alceu de Campos Rodrigues, 165 - V. N. Conceição

São Paulo/SP - Brasil - CEP 05409-001 cases described up to 1993), the tomographic aspects have already been described and have been said by some authors to be pathognomonic ${ }^{5.9}$.

Therefore, it is possible not only to diagnose the disease, but also to evaluate its extrarenal extension and to differentiate the focal and the diffuse forms, allowing for precise surgical planning. Treatment consists of total nephrectomy in the diffuse form and a partial nephrectomy when only a limited area is affected".

The purpose of our study is to present seven cases, describing their tomographic aspects and frequency, so as to help differentiate this disease from others.

\section{MATERIAL AND METHODS}

We reviewed CT studies of seven patients with an histopathologic diagnosis of XGP made between 1991 and 1993. Six of these seven patients were female and one was male, with ages ranging from 13 to 71 (mean age - 41 years). 
Table 1

Patients according to the presence and the site of stones, degree of hydronephrosis, and measurements of the less dense area of renal lesion

\begin{tabular}{lccccc}
\hline Patient & Stones & $\begin{array}{c}\text { Coraliform } \\
\text { Stones }\end{array}$ & Site & $\begin{array}{c}\text { Degree of } \\
\text { Hydronephrosis }\end{array}$ & $\begin{array}{c}\text { Density } \\
\text { (UH) }\end{array}$ \\
\hline AR & + & - & pyeloureteral junction & IV & $21-25$ \\
BFS & + & + & pyelo-calix & IV & $17-29$ \\
FLN & + & - & parenchyma/ureteral & I & - \\
JCM & + & + & pyelo-calix & IV & 14 \\
LACC & + & - & ureteral & IV & $22-24$ \\
MLF & + & + & pyelo-calix & IV & - \\
MVS & - & + & - & IV & $23-25$ \\
\hline
\end{tabular}

blurring of peritoneal fat due to hyperdense thick layers, mass images with the aspect of soft tissue or circundating liquid collections. Heterogeneity and asymmetric enlargement of paravertebral muscle and or subcutaneous cellular tissue were considered indications of abdominal involvement.
The exams were carried out using the Somatom DR (Siemens Medical System), with $8 \mathrm{~mm}$ wide cuts and an 8 or $16 \mathrm{~mm}$ increment, before and after one endovenous injection of $100-150 \mathrm{ml}$ iodine hydrosoluble contrast, measuring densities before and after contrast injection.

The tomographic parameters assessed were:

a) presence of stones and their sites.

b) renal dimensions. We considered the kidney "enlarged" when its longitudinal diameter exceeded $13 \mathrm{~cm}^{4}$.

c) degree of hydronephrosis, classification I - IV².

d) density measured in low-density areas.

e) presence of enhancement after endovenous contrast injection.

f) extra-renal damage (perirenal, pararenal and abdominal sites), with presence of heterogeneity or

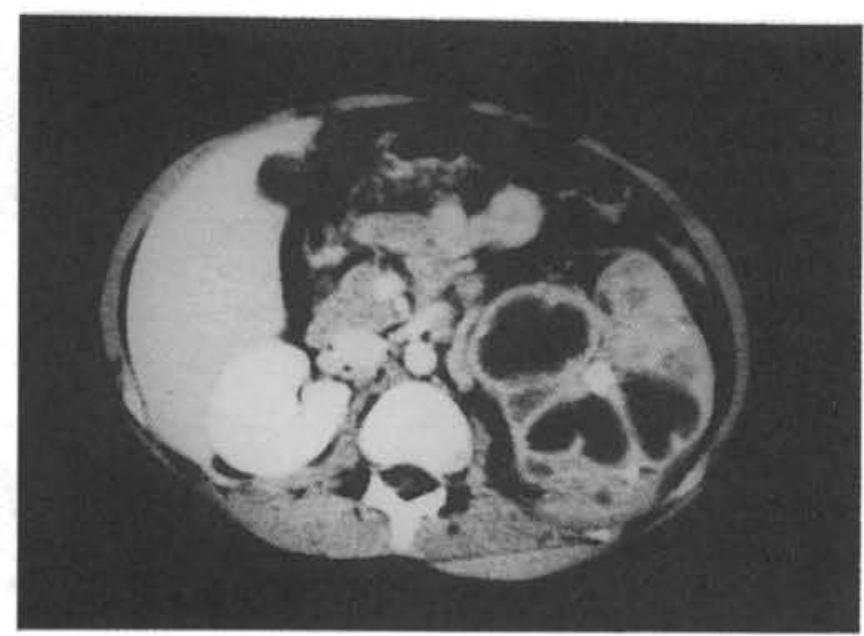

Figure 1 - Increase of left kidney volume showing peripheral enhancement and dilation of the collecting system with central calcification. This patient showed a normal inferior segment of the kidney.
Unilateral renal malfunction was evident in all patients; left malfunction in 5 (71 percent) and right in 2 (29 percent). In six cases, kidney enlargement was observed with grade IV hydronephrosis ( 86 percent), while in only one case (14 percent) there was a volumetric decrease with hydronephrosis grade I (Fig. 5). In six (86 percent), there were stones in the collecting system; in two (28 percent), there were stones in the renal parenchyma; and only one patient (14 percent) did not present any stones. In three of the six patients with stones in the collecting system, the stone was coraliform (Table 1).

The density of the low-density component of the lesion, measured from 14 to $29 \mathrm{UH}$, with no fat or gastype densities being observed. After the intravenous injection of contrast, there was a peripheral enhancement of the affected kidney (Fig.10), as well as extrarenal

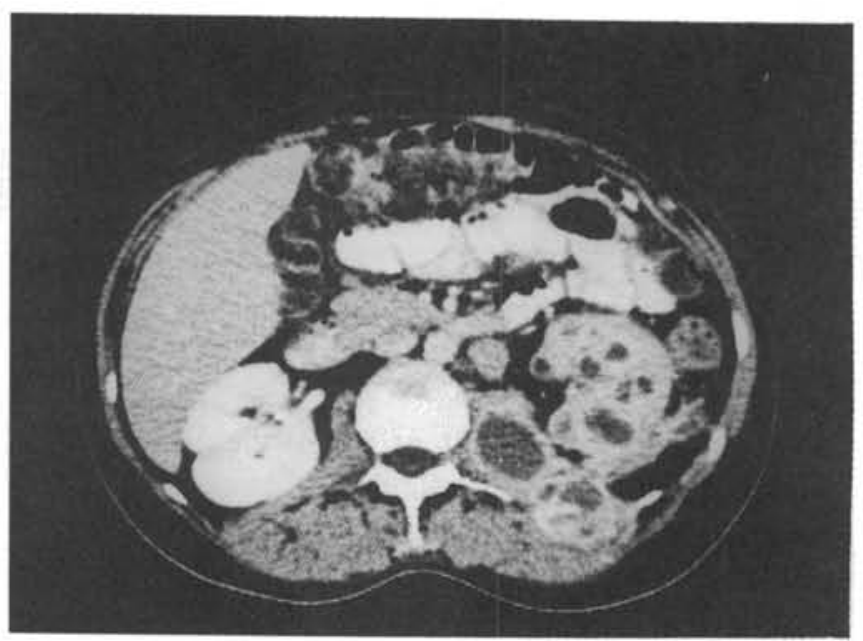

Figure 2- Left renal site occupied by a large collection of multiloci liquid which extended to the perirenal posterior pararenal and dorsal wall sites. A left enlargement of the psoas muscle can be observed. 
Table 2

Patients according to presence and site of extrarenal involvement

\begin{tabular}{lccc} 
Patient & perirenal & posterior pararenal & abdominal wall \\
\hline $\mathrm{AR}$ & + & + & - \\
$\mathrm{BFS}$ & + & + & + \\
$\mathrm{FLN}$ & + & + & + \\
$\mathrm{JCM}$ & + & + & - \\
LACC & + & + & + \\
MLF & + & + & - \\
MVS & + & + & +
\end{tabular}

damage extending to perirenal and posterior pararenal sites in all cases. In 4 cases ( 57 percent), the abdominal wall was involved (Table 2). There were no signs of involvement of retroperitoneal garylia, damage to other abdominal organs, or fistulae. All the cases were classified as XGP of the diffuse form, with one exception, which, due to the damage of the superior segment of the kidney, was considered to be a segmented form (Fig.1). Observed tomographic signs and their relative and absolute frequency are listed in Table 3.

\section{DISCUSSION}

XGP was described in 1916 by Schlogenhaufer, who called it staphylomycosis due to its resemblance to actinomycosis and to the presence of staphylococci ${ }^{17}$. The term XGP was used by Oberling, in 1935, due to its yellow color and to its granulomatous characteristic. XGP can be defined as a rare form of a chronic renal infection with

Table 3

Frequency of observed tomographic signs

\begin{tabular}{lc}
\hline \multicolumn{1}{c}{ Signs } & Frequency \\
\hline Enlargement of kidney & $86 \%(6 / 7)$ \\
Hydronephrosis grade IV & $86 \%(6 / 7)$ \\
& $14 \%(1 / 7)$ \\
Lithiasis & $86 \%(6 / 7)$ \\
Thick liquid collections & $100 \%(7 / 7)$ \\
Peripheral enhancement after & $100 \%(7 / 7)$ \\
contrast injection & $100 \%(7 / 7)$ \\
Extrarenal involvement &
\end{tabular}

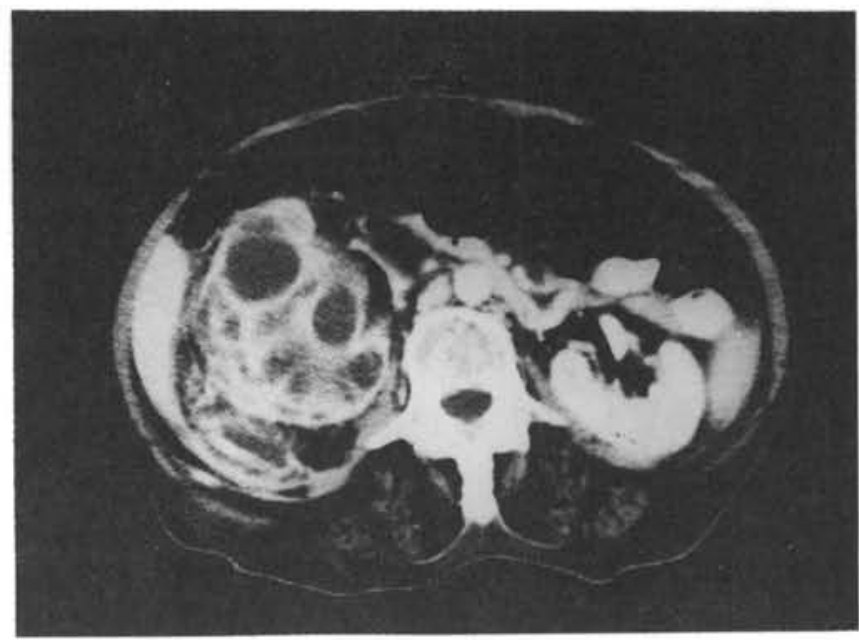

Figure 3 - XGP "bear claw" aspect. The right kidney is enlarged with liquid collections and presents intense peripheral enhancement. Inflammation to the perirenal site characterized by blurring of fat and the liquid collection.

diffuse or segmented damage, characterized by the destruction of parenchyma and the accumulation of macrophages containing lipids associated with intrarenal, peripyelic and perirenal fibrosis ${ }^{18}$. There is an association of XGP with a lipomatous degeneration that substitutes necrotic renal tissue, which originates in the renal sinus and spreads to the perirenal site, where it is encapsulated by the renal fascia'. ${ }^{1.9}$.

XGP can be classified as diffuse, segmented or focal, all showing similar clinical manifestations ${ }^{6}$. In the diffuse form the kidney is usually enlarged and distorted by the presence of multiple liquid collections which correspond to dilated calix or parenchymal destruction foci filled with purulent material. These alterations are frequently associated with extrarenal extension of the inflammation and perisinus fibrosis ${ }^{6}$. Segmented XGP is formed by two or more inflammatory masses that communicate with a calix or a duplicated unit, which usually is not dilated, although if does contain small obstructive stones close to the papilla ${ }^{6}$. The focal form shows the same alterations as the segmented form, although there is no communication with the collecting system and with a so-called focal xanthogranulomatous inflammation ${ }^{6,8,13}$. In our study, we observed six cases of the diffuse form and one case of the segmented form; all were treated with complete nephrectomy.

XGP pathogenesis is not yet fully understood, although the infection and obstruction of the urinary tract (13 are considered to be essential for this to occur). Other factors that seem to contribute to its installation are the alteration of lipid metabolism, immunity and lymphatic drainage, in addition to diabetes and renal papillary 
necrosis ${ }^{15}$. The incidence of XGP is variable, occurring at any age, with the description of a case at 48 days of age ${ }^{8 .}$ 18; however, it is more frequent in women in their fifties and sixties ${ }^{12}$.

Clinical manifestations are colic pain in the lower back ( 84 percent $)^{13}$, fever (55 percent), macroscopic hematuria ( 24 percent), weight loss (10 percent $)^{12}$ and a palpable mass in the lower back (39 percent) $(3,13,14$, 18); all these symptoms may be acute or subacute and occur without a previous history of urinary tract infection ${ }^{5}$.

Laboratory exams may be as non-specific as the clinical manifestations, with a normal uroculture in 40 percent of the patients, especially due to the renal exclusion found in these cases ${ }^{10}$. On the other hand, positive uroculture more frequently indicates the presence of $\mathrm{E}$. coli (49-67 percent), P. mirabilis (26-31 percent), S. aureus $(19$ percent $)$ and $P$. aeruginosa $(20 \text { percent })^{13.14 .16,18}$.

Other laboratory alterations found are increased ESR (100 percent), leukocytosis (70 percent), a decrease in hematocrit (67 percent), and creatinine alterations (46 percent $)^{14.16 .18}$.

Imagery diagnosis such as EU, APG, US and angiography suggest XGP, although there are some limitations which are especially due to the extrarenal extension of the disease (1).

EU may show renal exclusion (71-96 percent), nephromegaly (100 percent), lithiasis ( $71-82$ percent) and focal dilation of the collecting system (9 percent) $)^{3.13 .14}$. APG is used for cases involving renal exclusion, and demonstrates the level of obstruction, which is more frequently located at the ureteropyelic junction ${ }^{13.15}$.

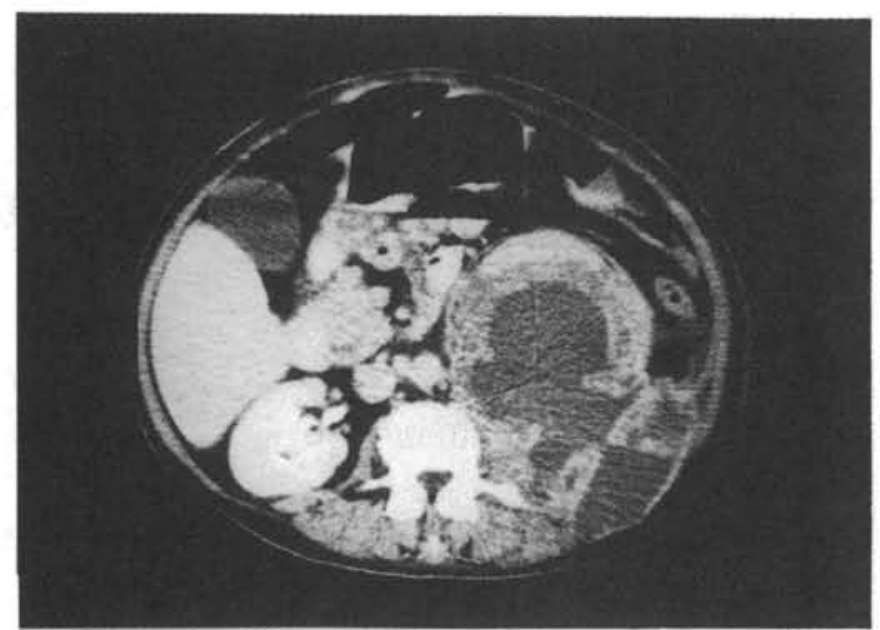

Figure 4 - Extrarenal involvement of XGP. Enlargement and heterogeneity of the psoas and paravertebral muscles to the left showing liquid collections associated with large thickening of posterior pararenal fascia.

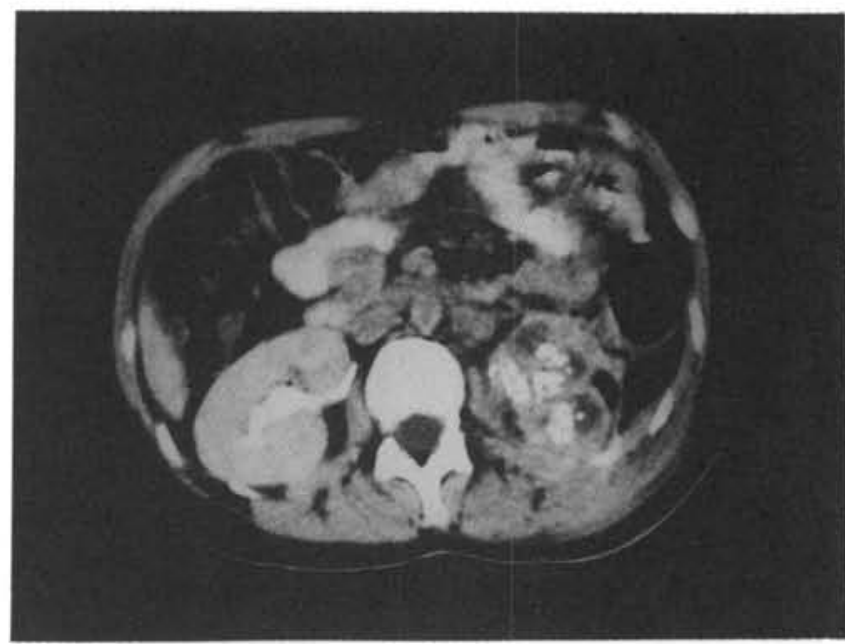

Figure 5 - Dotted calcifications and volumetric reduction of kidney similar to renal tuberculosis. There is an enlargement and heterogeneity of the abdominal dorsal wall.

Ultrasonography has, as its most important limitation, an inadequate retroperitoneal assessment ${ }^{10}$. It is interesting to mention that some authors had difficulties in describing the pyelocalix dilation in XGP patients ${ }^{13}$. On the other hand, it is very easy to diagnose the presence of liquid collections and renal stones, which even allows for a suggestion of the type of liquid.

There are two described ultrasonographic patterns in diffuse XPG. In most cases the kidney is enlarged, with smooth contours, and architecturally disarrayed due to the presence of several liquid masses which have a tendency to join and, in these cases, characterizes to a dilated collecting system with debris, corresponding to purulent material. Stones are frequently identified, except in those cases in which there is peripyelic fibrosis that may mimic the posterior acoustic shadows produced by calcifications ${ }^{6}$. In another less frequent and non-specific form of presentation, the renal site is noted to have been occupied by an extensive heterogeneic formation that is predominantly liquid. The segmented form is very similar to the first form described, although part of the affected kidney is preserved ${ }^{6}$. Difficulty in diagnosis occurs in the focal form, because its presentation in the ultrasonogram is often undistinguishable from a solid or cystic kidney neoplasm or even from an abscess ${ }^{6.7}$.

Finally, it is important to remember that angiography, when used to distinguish an XGP from a renal carcinoma, only does so in $25-75$ percent of the cases, those with a hypovascular (50 percent) or an avascular ( 25 percent) pattern, different from what is usually found in the hypernephana ${ }^{13}$. This presentation depends on the quantity of neovascularization of granulation tissue ${ }^{7}$. 
Magnetic resonance has not shown any significant advances up to this moment in the diagnosis of XGP, and is not able to provide any information beyond that given by CT (9). However, it is important to remember that the low toxicity of the paramagnetic contrast, as well as the possibility of receiving orthogonal images in three planes, may make MR useful for those patients who are allergic to iodine or need more detailed surgical planning.

In our study, CT showed a constant pattern similar to those described by other authors ${ }^{12,13,14}$. We observed a diffuse increase in renal volume in most of the patients $\mathrm{s}^{6.7}$, except for one who presented the segmented form of the disease. In this case, besides being enlarged, the kidney kept its usual form, and peripheral enhancement was noted that may correspond to compressed residual parenchyma or to a capsule of inflammatory tissue ${ }^{5}$ (Fig.1).

It is important to observe that the radial distribution of the liquid cavities which were found in the kidney resembles the distribution of the collecting system and has the aspect of a "bunch of grapes" or a "bear claw" as described by some authors ${ }^{12.13}$ (Figs. 2 and 3 ).

The density measures obtained (14-29 UH) do not differ significantly from those found by Goldman et al. $(10-15 \mathrm{UH})^{5}$, if we remember that all these rates indicate a thick liquid and that different calibrations of the equipment used may lead to small differences. On the other hand, we emphasize that in no case did we find densities similar to fat, as was suggested by Acunas et al., who considered this infrequent'.

It was not surprising to find a frequent extrarenal extension of XGP that was drained in all studied cases and easily identified in several retroperitoneal sites and dorsal wall (Fig. 4). The importance in defining extrarenal damage resides in adequate surgical planning, thus avoiding any undesirable fistulae ${ }^{12,13}$, which has even suggested a classification of the XGP through CT in: State I when the disease is restricted to renal parenchyma, in State II when there is perirenal involvement, and in State III when there is peri and pararenal involvement ${ }^{3}$. Therefore, it may be interesting to define a State IV when there is damage to the abdominal wall.

Despite the characteristic aspect of the XGP in the $\mathrm{CT}$, a differential diagnosis with hypernephroma, renal tuberculosis ( $\mathrm{Tb}$ ), and pyohydronephrosis must be made. Hypernephroma may be similar to XGP in its focal form when studied by the US and CT, and, even more, 50 when in its cystic form, although this is relatively rare in adults. In these cases, a more crude type calcification with a coraliform aspect may help in the diagnosis of $\mathrm{XGP}^{13.16}$. When this is not possible and there are no retroperitoneal ganglia in the tomographic exam (rare in XGP) or other malignity signs (e.g. hepatic metastases), selective arteriography may be useful if it demonstrates an avascular pattern therefore ruling out the blastomatose origin of the process. On the other hand, a hypo or hypervascular pattern may be found in XGP and hypernephroma ${ }^{15}$.

Renal $\mathrm{Tb}$ usually evolves with a decrease in renal volume and with calcifications somewhat different from XGP which are more pointed in shape. When XGP leads to renal reduction, differential diagnosis with $\mathrm{Tb}$ may be extremely difficult as in one of the studied cases (Fig. 5).

Finally, pyohydronephrosis is considered by many authors to be an initial stage or a precursor of $\mathrm{XGP}^{\prime \prime}$, and has a very similar pattern.

Other differential diagnoses, which are more rare that should be remembered, are lipoma and liposarcoma, in which XGP coexists with an intense gradual replacement of granulation tissue for adipose tissue of an unknown origin'.

\section{CONCLUSION}

Although some authors suggest that preoperative diagnosis through imagery exams should not be done in any case, but cannot justify this ${ }^{3}$, we believe that, according to the results found in our study and literary review, that computed tomography is a method which allows identification of very characteristic signs indicating a preoperative diagnosis of XGP. These signs are: a) increase in renal volume; b) hydronephrosis; c) renal/ureteral lithiasis; c) collections of thick fluid; d) peripheral enhancement after contrast injection; f) extrarenal involvement of perirenal, posterior pararenal and abdominal wall sites. 


\section{RESUMO}

Os autores apresentam a sua experiência em 7 pacientes com diagnóstico anátomopatológico de Pielonefrite Xantogranulomatosa (PXG) submetidos a tomografia computadorizada (TC) pré-operatória. Os parâmetros estudados e seus resultados foram: a) presença de cálculos em $86 \%$ dos casos, b) volume renal frequentemente aumentado,c) hidronefrose, d) medidas de densidade variando entre 14 e $29 \mathrm{HU}, e)$ presença de realce em todos os casos, f) comprometimento extra-renal, também presente em todos os casos. A TC demonstrou ser um método bastante fidedigno na caracterização da PXG e sua extensāo extra-renal.

\section{REFERENCES}

1. Acunas B, Acunas G, Rozanes I. Coexistent Xantogranulomatosa Pyelonephritis and massive replacement lipomatosis of the kidney: CT diagnosis. Urol Radiol 1990;12:88-90.

2. Barbaric ZL. "Urinary Tract Obstruction". In: Barbaric Z, ed. Principles of Genitourinary Radiology. New York:Thieme, 1991:110-131.

3. Chuang CK, Lai MK, Chang P, et al. Xantogranulomatous Pyelonephritis: Experience in 36 cases. J Urol 1992;147:333-6.

4. Emamian SA, Nielsen MB, Pedersen JF. Kidney dimensions at sonography: Correlation with age, sex and habitus in 665 adults volunteers. AJR 1993;160:83-6.

5. Goldman SM, Hartman DS, Fischman EK, Finizio JP, Gatewood OM, Siegelman SS. CT of Xantogranulomatous Pyelonephritis radiologic-pathologic correlation. AJR 1984;142:963-9.

6. Hartman DS, Goldman SM, Davis CJ, Isbister SS, Sanders RC. Xantogranulomatous Pyelonephritis: Sonographic pathologic correlation of 16 cases. J Ultrasound Med 1984;3:481-8.

7. Hayes WS, Hartman DS, Sesterhenn IA. In: Archives of the AFIP Xantogranulomatous Pyelonephritis. Radiographics 1991;11:485-498.

8. Hughes PM, Gupta SC, Thomas NB, et al. Case report: Xantogranulomatous Pyelonephritis in childhood. Clinical Radiology 1990;41:360-2.
9. Laugareil P, Blery M, Chagnon S, et al. Pyelonephritis Xantogranulomateuse avec proliferation graisseuse de la loge renale. J Radiol 1989;70:295-7.

10. Madero JM, Garcia JA, Sexmilo IE. Pyelonefritis Xantogranulomatosa: posibilidades de diagnostico por la imagem. An Esp Pediatr 1990;33(1):50-3.

11. Malek RS, EIder JS. Xantogranulomatous Pyelonephritis: A critical analysis of 26 cases and of the literature. J Urol 1978;119:589-593.

12. Paez AB, Silmi AM, Diego AG, et al. Pyelonefritis Xantogranulomatosa: Estudio Retrospectivo. Arch Esp de Urol 1990;43:843-9.

13. Parker MD, Clark RL. Evolving concepts in the diagnois of Xantogranulomatous Pyelonephritis. Urol Radiol 1989;11:7-15.

14. Petronic V. Xantogranulomatous Pyelonephritis. Br J Urol 1989;64:336-8.

15. Rafael RB, Kosovsky PA, Markisz JA. Xantong. Pyelonephritis in an infant. Urology 1991;36:553-6.

16. Shah M, Haagan R. Focal Xantogranulomatous Pyelonephritis simulating a renal tumor: CT characteristics. J Comput Assist Tomogr 1989;13:712-3.

17. Schlagenhaufer F. Uber eigentumliche Staphylomykosen der Nieven und des pararenalen Bindegewebes. Frankfurt Z Pathol 1916;19:139-148.

18. Zafaranhas S, Gerard PS, Bryk D. Xant Pyelon in Children: Analysis by diagnostic modalities. Urol Radiol 1990; 12:18-21. 